\title{
Bitcoin and CEE stock markets: fresh evidence from using the DECO-GARCH model and quantile on quantile regression
}

\author{
Ngo Thai Hung \\ Faculty of Economics and Law, University of Finance-Marketing, \\ Ho Chi Minh City, Vietnam
}

Bitcoin prices and CEE stock markets

\begin{abstract}
Purpose - This study examines the inter-linkages between Bitcoin prices and CEE stock markets (Hungary, the Czech Republic, Poland, Romania and Croatia).

Design/methodology/approach - The dynamic contemporaneous nexus has been analyzed using both the multivariate DECO-GARCH model proposed by Engle and Kelly (2012) and quantile on quantile (QQ) methodology proposed by Sim and Zhou (2015). Our study is implemented using the daily data spanning from 6 September 2012 to 12 August 2019.

Findings - First, the findings show that the average return equicorrelation across Bitcoin prices and CEE stock indices are positive, even though it is found to be time-varying over the research period shown. Second, the Bitcoin-CEE stock market association has positive signs for most pairs of quantiles of both variables and represents a rather similar pattern for the cases of Poland, the Czech Republic and Croatia. However, a weaker and primarily negative connectedness is found for Hungary and Romania, respectively. Furthermore, the interconnectedness between the co-movements in the Bitcoin market and stock returns changes significantly across quantiles of both variables within each nation, indicating that the Bitcoin-stock market relationship is dependent on both the cycle of the stock market and the nature of Bitcoin price shocks.

Practical implications - The evidence documented in this study has significant implications for divergent economic agents, including global investors, risk managers and policymakers, who would benefit from a comprehensive knowledge of the Bitcoin-stock market relationship to build efficient risk-hedging models and to conduct appropriate policy reactions to information spillover effects in different time horizons.

Originality/value - This paper is the first study employing both the multivariate DECO-GARCH model and QQ methodology to shed light on the nexus between Bitcoin prices and the stock markets in CEE countries. The DECO model uses more information to compute dynamic correlations between each pair of returns than standard dynamic conditional correlation (DCC) models, declining the estimation noise of the correlations. Besides, QQ approach allows us to capture some nuanced features of the Bitcoin-stock market relationship and explore the interdependence in its entirely. Therefore, the main contribution of this article to the related literature in this field is significant.
\end{abstract}

Keywords CEE stock markets, DECO, Bitcoin, Quantile on Quantile approach

Paper type Research paper

\section{Introduction}

Cryptocurrencies are considered as an attractive and alternative investment asset for the purposes of portfolio diversification, since they represent various variations in returns that

(C) Ngo Thai Hung. Published in European Journal of Management and Business Economics. Published by Emerald Publishing Limited. This article is published under the Creative Commons Attribution (CC BY 4.0) licence. Anyone may reproduce, distribute, translate and create derivative works of this article (for both commercial and non-commercial purposes), subject to full attribution to the original publication and authors. The full terms of this licence may be seen at http://creativecommons.org/licences/by/4.0/ legalcode

The authors are grateful to the anonymous referees of the journal for their extremely useful suggestions to improve the quality of the article. Usual disclaimers apply.

Funding: The author received no financial support for the research, authorship and/or publication of this article.

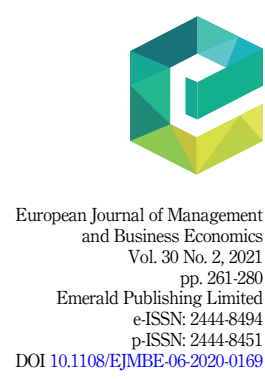


EJMBE 30,2 show lower connections versus other traditional financial assets (Kang et al. 2019a). The rapid development of cryptocurrency markets and the upsurge in cryptocurrencies as novel financial asset classes consequently provides a robust opportunity to examine several as yet unexpected aspects of cryptocurrencies (Gil-Alana et al., 2020). Specifically, during recent global economic and financial crises, the contentious traits of Bitcoin have been considered as a hedge or safe haven like gold. Bitcoin market is also considered as hedge or safe haven asset by an array of academics and international investors (Wei, 2018; Brauneis and Mestel, 2018; Bouri et al., 2019; Antonakakis et al., 2019; Paule-Vianez et al., 2020). Also, Bitcoin has been considered as an indispensable asset that demonstrates both the standard financial asset and a speculative asset (Wang et al., 2020b). Therefore, the information transmission running from Bitcoin prices to other traditional financial markets might help in investment and policy decision purposes (Salisu et al., 2019).

According to Zhang et al. (2021), it is a potential source of instability to financial markets since the Bitcoin market has witnessed rapid development and presented extreme price volatility. As a result, it is necessary to systematically understand the interconnection between Bitcoin and other financial markets for the sake of decision in connection with asset allocation, risk management and financial stability. Moreover, it is also essential to select the advanced and refined models to analyze the dynamic risk transmission from Bitcoin to other conventional financial assets due to the sophistication of the Bitcoin market (Bouri et al., 2019; Antonakakis et al., 2019).

Furthermore, the research of the relationship between the Bitcoin market and stock returns is useful for policymakers to enhance the regulatory systems in various economies. Several scholars have argued that the Bitcoin market is a bubble that will burst in the future and have risk spillover effects on other financial asset classes (Zeng et al., 2020). Hence, any evidence of transmission from Bitcoin prices to other markets and vice versa, may impact asset allocation and risk management for investors.

Nevertheless, there remains a lack of a better understanding of the interplay between cryptocurrencies and other financial markets (Zeng et al., 2020). Consequently, the purpose of this article is to unveil the equicorrelation and interconnectedness between Bitcoin and stock markets in five Central and Eastern European countries (Hungary, Poland, Romania, the Czech Republic and Croatia) via the combination of the multivariate DECO-GARCH model of Engle and Kelly (2012) and quantile on quantile (QQ) methodology proposed by Sim and Zhou (2015). These models allow for capturing the linkages and measuring intercorrelation of Bitcoin and the CEE stock markets to enrich the literature on this subject.

The current study belongs to the literature on Bitcoin finance and economics and connects to studies on the connectedness between Bitcoin prices and stock markets. As a result, this paper adds to the existing literature in serval ways. The first contribution is that it estimates the dynamic correlations between Bitcoin prices and CEE stock market indices by using an MGARCH model with the DECO specification. Engle and Kelly (2012) proposed the dynamic equicorrelation GARCH (DECO-GARCH) model in which the average of the conditional correlations is set to equal the average of all pair correlations. Thus, the time variations in the connectedness of all markets under study are measured (Kang et al. 2019a, b; Kang and Yoon, 2019; Bouri et al., 2020; McIver and Kang, 2020). In addition, we employ the QQ approach to capture the relatedness between co-movements in Bitcoin prices and CEE stock markets to be conditional on the stock market cycle and the size and sign of Bitcoin prices (Ferrer et al., 2019). More precisely, the $Q Q$ methodology not only measures the heterogeneous interaction between Bitcoin market and stock return variations in the $\mathrm{CEE}$ countries at distinct points of the conditional distribution of Bitcoin market, since the standard quantile regression does, but it also models the quantile of Bitcoin prices as a function of the quantile of stock market indices (Shahbaz et al., 2018; Haseeb et al., 2020; Sinha et al., 2020). 
We find a positive equicorrelation between Bitcoin and the CEE stock markets, which is relatively weak during the period shown. What is more, we provide evidence that the interconnectedness between the co-movements in the Bitcoin market and stock returns changes significantly across quantiles of both variables within each nation, indicating that the Bitcoin-stock market relationship is dependent on both the cycle of the stock market and the nature of Bitcoin price shocks. Besides, our findings illustrate the important heterogeneity Bitcoin market in the degree of correlation to the CEE stock indices over time, boosting our significant understanding of the economic channels through which the Bitcoin-stock market relationship in the $\mathrm{CEE}$ region are linked. Finally, our analysis has crucial implications concerning risk management, asset allocation and regulatory formulation.

The rest of this paper is structured as follows. Section 2 provides a literature review. Section 3 presents a description of the data and methodologies. Section 4 documents the empirical results. Section 5 concludes the study with policy implications.

\section{Literature review}

The emergence of Bitcoin and other cryptocurrencies in the market has been studied during this decade (Gil-Alana et al., 2020). The literature on cryptocurrencies has covered a wide range of divergent aspects, beginning with the technical and investment characteristics of Bitcoin in relation to risk and returns (Wei, 2018; Tan et al., 2020; Omane-Adjepong et al., 2019; Kosc et al., 2019; Da Gama Silva et al., 2019; Brauneis and Mestel, 2018; Bouri, et al., 2019; Antonakakis et al., 2019; Yi et al., 2018; Koutmos, 2018). There are vast sum of studies focusing on Bitcoin suitability as an asset to diversify the risks of other traditional assets, which is consistent with the purpose of this paper. We effectively restrict our concentration on the literature with regard to the connectedness between Bitcoin and other traditional asset classes.

This article brings an additional to fruit-bearing studies on the interdependence across traditional assets. The relationship among different markets is reinforced by the financial globalization. For instance, López-Cabarcos et al. (2019) analyze the natural behavior of Bitcoin and the impact that investor sentiment, S\&P 500 and VIX returns have on Bitcoin volatility. They find that Bitcoin volatility is more unstable in specific period, while S\&P 500, VIX returns and sentiment impact Bitcoin volatility in stable periods. Wang et al. (2020a) show that Bitcoin prices represent noticeably higher trading volume and volatility during hours that occur simultaneously with the daytime trading hours of European and US stock markets. More recently, Corbet et al. (2020) investigate the connectedness between news coverage and Bitcoin returns and provide evidence of macroeconomic indicators have a significant effect on Bitcoin returns. They also suggest that the developing cryptocurrency market is further maturing through associations with macroeconomic news. Paule-Vianez et al. (2020) look into whether Bitcoin behaves as a safe-haven asset and conclude that Bitcoin's spillover effects increase during more uncertain times like gold. As a result, Bitcoin illustrates characteristics of investment assets, in particular safe havens.

Recently, the majority of studies center on the interactions between cryptocurrency and stock markets. Mensi et al. (2020) investigate the connectedness between Bitcoin and the World stock market, regional Islamic stock markets and Sukuk markets. They provide many interesting findings on the co-movements among asset classes. The relationship is stronger and similar direction at lower frequencies, but in the opposite direction at high frequencies, indicating the benefits from diversification with Bitcoin are somewhat less for long-term investors and benefits of hedging in the short run through diversification in Bitcoin and Islamic equity markets. In the same vein, Wang et al. (2020b) focus on the relationship between Bitcoin and the stock markets and reveal that the S\&P 500 and Dow Jones indices has a relatively impact on Bitcoin, while the effect caused by them on Bitcoin is significantly weak. Using daily data, Zhang et al. (2021) find that reasonable evidence to imply the persistence of downside risk spillover between Bitcoin and equity markets would be time dependent. Similar
Bitcoin prices and CEE stock markets 
EJMBE 30,2

\section{4}

to our approach, Zeng et al. (2020) explore the connectedness between Bitcoin and conventional financial assets. Their results show that the relationship between Bitcoin and traditional assets is significantly weak. Specifically, the presence of a nonlinear and asymmetric pattern of the spillover effects between Bitcoin and conventional assets is highlighted.

A limited number of studies have analyzed the interrelatedness between cryptocurrencies and financial and economic assets utilizing various methodologies. Salisu et al. (2019) investigate the role of Bitcoin market in stock markets of the G7 countries. The authors provide evidence that Bitcoin prices better predict the stock returns of the G7 countries than their respective macroeconomic variables. Kang et al. (2019b) give straightforward insights into for investors to manage their investment risk by examining the dynamic equicorrelation nexus between Bitcoin and four major investment assets (S\&P 500, US dollar, Treasury bonds and Bitcoin other asset classes. They find that Bitcoin can be used as an effective safe haven for investors by offering invaluable information to reduce downside risk, hence enhancing diversification benefits in optimal asset allocation.

At the same time, more efforts have been made to estimate the risk-return, volatility and benefits for investors. Gil-Alana et al. (2020) explore the bilateral relationship between six major cryptocurrencies and six stock market indices, showing that there is no evidence of cointegration between the cryptocurrencies and the stock market indexes, which means that the cryptocurrencies are decoupled from the mainstream financial and economic assets. Besides, their results also suggest the important role of cryptocurrencies in investor portfolios as they serve as a diversification option for investors. In a similar fashion, Corbet et al. (2018) analyze the connectedness between the common cryptocurrencies and an array of other financial assets in the different time scales and frequency domains. They provide evidence of the relative isolation of the cryptocurrencies from the financial and economic assets and show that cryptocurrencies would give diversification benefits for investors with short investment horizon. In the same year, Zhang et al. (2018) confirm several major cryptocurrencies are inefficient markets and indicate that Cryptocurrency Composite Index and Down Jones Industrial Average are persistently cross-correlated.

Various studies have used divergent estimation techniques to capture the Bitcoinfinancial asset relationship with regard to the specification of econometric models. Several papers have employed linear models, while others have utilized nonlinear models to analyze the Bitcoin prices and other traditional financial asset classes. However, the most popular techniques used are GARCH family models (López-Cabarcos et al., 2019), Granger causality test (Wang et al., 2020b; Kang et al., 2019b), Spillover index (Mensi et al., 2020; Zeng et al., 2020; Corbet et al., 2018), MF-DCCA (Zhang et al., 2018). In this paper, we employ the DECO-GARCH model alongside $\mathrm{QQ}$ regression approach to shed light on the dynamic interplay between the Bitcoin market and CEE stock returns. Engle and Kelly (2012) introduce the dynamic equicorrelation GARCH (DECO-GARCH) model in which the average of the conditional correlations is set to equal the average of all pair correlations. Thus, the time variations in the connectedness of all markets under study are measured. Many studies have used a DECOGARCH framework for financial markets and asset classes to measure the time-varying correlation functions (Kang et al. 2019a, b; Kang and Yoon, 2019; Bouri et al., 2020; McIver and Kang, 2020). Additionally, in order to capture both the heterogeneous interaction between Bitcoin and stock returns at distinct points of the conditional distribution of Bitcoin returns and the quantile of Bitcoin prices as a function of the quantile of stock movements, the $\mathrm{QQ}$ approach proposed by Sim and Zhou (2015) has been used (Shahbaz et al., 2018; Haseeb et al., 2020; Sinha et al., 2020; Ferrer et al., 2019). Therefore, the present study intends to fill this gap by examining the interdependence between Bitcoin prices and the CEE stock markets, which takes into consideration structural breaks, nonlinearity, asymmetry and regime shifts, among others.

The majority of the literature results are reported in Table 1. 


\begin{tabular}{|c|c|c|c|c|c|}
\hline Authors & Assets & Periods & Method & Result & Bitcoin prices \\
\hline $\begin{array}{l}\text { Brauneis and } \\
\text { Mestel (2018) }\end{array}$ & Cryptocurrencies & 2015-2017 & GARCH & $\begin{array}{l}\text { Cryptocurrencies become } \\
\text { less predictable }\end{array}$ & markets \\
\hline Wei (2018) & Cryptocurrencies & 2013-2018 & $\begin{array}{l}\text { Amihud } \\
\text { illiquidity ratio }\end{array}$ & $\begin{array}{l}\text { Signs of autocorrelation } \\
\text { and non-independence }\end{array}$ & \\
\hline Yi et al. (2018) & Cryptocurrencies & 2013-2018 & LASSO-VAR & Tightly interconnected & \\
\hline $\begin{array}{l}\text { Koutmos } \\
(2018)\end{array}$ & Cryptocurrencies & $2015-2018$ & Spillover index & $\begin{array}{l}\text { Return and volatility } \\
\text { spillovers have risen } \\
\text { steadily over time }\end{array}$ & 265 \\
\hline $\begin{array}{l}\text { Corbet et al. } \\
\text { (2018) }\end{array}$ & $\begin{array}{l}\text { MSC GSCI, COMEX, S\&P } \\
500, \text { VIX and ITTR110 }\end{array}$ & 2013-2017 & Spillover index & $\begin{array}{l}\text { Relative isolation of these } \\
\text { assets from the financial } \\
\text { and economic assets }\end{array}$ & \\
\hline $\begin{array}{l}\text { Zhang et al. } \\
\text { (2018) }\end{array}$ & $\begin{array}{l}\text { Dow Jones Industrial } \\
\text { Average and } \\
\text { cryptocurrencies }\end{array}$ & 2013-2018 & $\begin{array}{l}\text { MF-DFA and MF- } \\
\text { DCCA }\end{array}$ & $\begin{array}{l}\text { Bitcoin, Ripple, Ethereum, } \\
\text { NEM, Stellar, Litecoin, } \\
\text { Dash, Monero and Verge } \\
\text { are inefficient markets }\end{array}$ & \\
\hline $\begin{array}{l}\text { Omane- } \\
\text { Adjepong et al. } \\
\text { (2019) }\end{array}$ & Cryptocurrencies & 2015-2018 & $\begin{array}{l}\text { ARFIMA- } \\
\text { FIGARCH, } \\
\text { Wavelet analysis }\end{array}$ & $\begin{array}{l}\text { Efficiency and volatility } \\
\text { persistence to be highly } \\
\text { sensitive to time-scale }\end{array}$ & \\
\hline $\begin{array}{l}\text { Kosc et al. } \\
\text { (2019) }\end{array}$ & Cryptocurrencies & 2014-2017 & $\begin{array}{l}\text { Portfolio } \\
\text { performance }\end{array}$ & $\begin{array}{l}\text { Dominance of the short- } \\
\text { term contrarian effect over } \\
\text { both momentum effect } \\
\text { and the benchmark } \\
\text { portfolios }\end{array}$ & \\
\hline $\begin{array}{l}\text { Da Gama Silva } \\
\text { et al. (2019) }\end{array}$ & Cryptocurrencies & 2015-2018 & Herding behavior & $\begin{array}{l}\text { Extreme periods of } \\
\text { adverse herd behavior }\end{array}$ & \\
\hline $\begin{array}{l}\text { Bouri et al. } \\
\text { (2019) }\end{array}$ & Cryptocurrencies & 2013-2017 & $\begin{array}{l}\text { Copula-Granger- } \\
\text { causality }\end{array}$ & $\begin{array}{l}\text { Trading volume Granger } \\
\text { causes extreme negative } \\
\text { and positive returns of all } \\
\text { cryptocurrencies }\end{array}$ & \\
\hline $\begin{array}{l}\text { Antonakakis } \\
\text { et al. (2019) }\end{array}$ & Cryptocurrencies & 2015-2018 & TVP-FAVAR & $\begin{array}{l}\text { Connectedness across } \\
\text { several cryptocurrencies } \\
\text { exhibits large dynamic } \\
\text { variability }\end{array}$ & \\
\hline $\begin{array}{l}\text { López- } \\
\text { Cabarcos et al. } \\
\text { (2019) }\end{array}$ & $\begin{array}{l}\text { S\&P } 500 \text { Index, VIX Index, } \\
\text { Bitcoin prices }\end{array}$ & 2016-2019 & $\begin{array}{l}\text { GARCH and } \\
\text { EGARCH }\end{array}$ & $\begin{array}{l}\text { Bitcoin volatility is more } \\
\text { unstable in speculative } \\
\text { periods }\end{array}$ & \\
\hline $\begin{array}{l}\text { Wang et al. } \\
\text { (2020a) }\end{array}$ & Bitcoin & 2015-2018 & HSVol & $\begin{array}{l}\text { Bitcoin market exhibits } \\
\text { noticeably higher trading } \\
\text { volume }\end{array}$ & \\
\hline $\begin{array}{l}\text { Salisu et al. } \\
\text { (2019) }\end{array}$ & $\begin{array}{l}\text { The stock price indexes of } \\
\text { the G7 countries, Bitcoin }\end{array}$ & $2010-2017$ & $\begin{array}{l}\text { Baseline } \\
\text { predictive model }\end{array}$ & $\begin{array}{l}\text { The stock returns of the } \\
\text { G7 countries are better } \\
\text { predicted by Bitcoin }\end{array}$ & \\
\hline $\begin{array}{l}\text { Corbet et al. } \\
(2020)\end{array}$ & $\begin{array}{l}\text { Bitcoin, S\&P } 500 \text { and } \\
\text { macroeconomic indicators }\end{array}$ & 2010-2019 & Regression & $\begin{array}{l}\text { News related to durable } \\
\text { goods and unemployment } \\
\text { to significantly affect } \\
\text { Bitcoin returns }\end{array}$ & \\
\hline \multirow[t]{2}{*}{$\begin{array}{l}\text { Paule-Vianez } \\
\text { et al. (2020) }\end{array}$} & Bitcoin and EPU & 2010-2019 & $\begin{array}{l}\text { Simple linear } \\
\text { regression and } \\
\text { quantile } \\
\text { regression } \\
\text { models }\end{array}$ & $\begin{array}{l}\text { Bitcoin shows } \\
\text { characteristics of } \\
\text { investment assets }\end{array}$ & \\
\hline & & & & (continued) & $\begin{array}{r}\text { Table } 1 . \\
\text { Summary of literature }\end{array}$ \\
\hline
\end{tabular}




\section{EJMBE 30,2}

\begin{tabular}{|c|c|c|c|c|}
\hline Authors & Assets & Periods & Method & Result \\
\hline $\begin{array}{l}\text { Mensi et al. } \\
(2020)\end{array}$ & $\begin{array}{l}\text { Bitcoin, the Dow Jones } \\
\text { World Stock Market } \\
\text { Index, regional Islamic } \\
\text { stock markets and Sukuk } \\
\text { markets }\end{array}$ & 2010-2018 & Wavelet analysis & $\begin{array}{l}\text { The co-movement is } \\
\text { stronger and in the same } \\
\text { direction at lower } \\
\text { frequencies }\end{array}$ \\
\hline $\begin{array}{l}\text { Wang et al. } \\
(2020 \mathrm{~b})\end{array}$ & $\begin{array}{l}\text { Cryptocurrencies, S\&P } \\
\text { 500, NASDAQ and Dow } \\
\text { Jones Industrial Average) }\end{array}$ & 2013-2018 & VAR & $\begin{array}{l}\text { The S\&P } 500 \text { and the Dow } \\
\text { Jones indexes have an } \\
\text { advantageous effect on } \\
\text { Bitcoin }\end{array}$ \\
\hline $\begin{array}{l}\text { Zhang et al. } \\
\text { (2021) }\end{array}$ & $\begin{array}{l}\text { Bitcoin, Dollar index, } \\
\text { MSCI, Bond and GSCI }\end{array}$ & 2011-2020 & Expectile VaR & $\begin{array}{l}\text { Existence of downside } \\
\text { risk spillover between } \\
\text { Bitcoin and four assets }\end{array}$ \\
\hline $\begin{array}{l}\text { Zeng et al. } \\
(2020)\end{array}$ & $\begin{array}{l}\text { Cryptocurrencies, S\&P } \\
\text { 500, VIX, WTI and Gold }\end{array}$ & 2012-2019 & Spillover index & $\begin{array}{l}\text { Connectedness between } \\
\text { Bitcoin and conventional } \\
\text { assets is weak }\end{array}$ \\
\hline $\begin{array}{l}\text { Gil-Alana et al. } \\
(2020)\end{array}$ & $\begin{array}{l}\text { Cryptocurrencies, Bond, } \\
\text { Dollar, Gold, VIX, GSCI } \\
\text { and S\&P 500 }\end{array}$ & 2015-2018 & $\begin{array}{l}\text { Fractional } \\
\text { integration and } \\
\text { Cointegration }\end{array}$ & $\begin{array}{l}\text { No cointegration between } \\
\text { the six cryptocurrencies } \\
\text { and stock markets }\end{array}$ \\
\hline
\end{tabular}

\section{Methodology}

\subsection{The DECO-GARCH model}

Engle and Kelly (2012) develop the dynamic equicorrelation GARCH (DECO-GARCH) model at which the average of the conditional correlation is referred to as equal the average of all pair correlations. Therefore, we can estimate the time-varying linkages across markets over the study period shown. Unlike the standard DCC model proposed by Engle (2002), the DECO framework allows large-scale correlation matrices to be addressed.

We have a vector of $n$ return series $r_{t}=\left[r_{1, t}, \cdots, r_{n, t}\right]^{\prime}$. The following ARMA $(1,1)$ process has been estimated:

$$
r_{t}=\mu+\phi r_{t-1}+\varepsilon_{t}+\xi \varepsilon_{t-1}, \text { with } \varepsilon_{t}=u_{t} h_{t}
$$

where $\mu$ is a constant vector, and $\varepsilon_{t}=\left[\varepsilon_{1, t}, \cdots, \varepsilon_{n, t}\right]^{\prime}$ is a vector of residuals.

The dynamic conditional correlation (DCC) is employed. Engle (2002) introduced this estimator to capture the dynamic time-varying behavior of conditional covariance. The conditional covariance matrix $H_{t}$ is now defined as,

$$
H_{t}=D_{t} R_{t} D_{t}
$$

where $D_{t}=\operatorname{diag} \sqrt{\left\{H_{t}\right\}}$ is the diagonal matrix with conditional variances along the diagonal, and $R_{t}$ is the time-varying correlation matrix.

A GARCH $(1,1)$ specification of each conditional variance can be written as,

$$
\begin{gathered}
h_{i, t}=c+a_{i} \varepsilon_{i, t-1}^{2}+b_{i} h_{i i, t-1} \\
h_{i j, t}=\rho_{i j} \sqrt{h_{i i, t} h_{j, t}}, i, j=\overline{1, n}
\end{gathered}
$$

where $c$ is a $n \times 1$ vector, $a_{i}$ and $b_{i}$ are diagonal $(n \times n)$ matrices.

Eqn (2) can be re-parameterized with standardized returns as follows, $e_{t}=D_{t}^{\prime} \varepsilon_{t}$

$$
E_{t-1} e_{t} e_{t}^{\prime}=D_{t}^{-1} H_{t} D_{t}^{-1}=R_{t}=\left[\rho_{i j, t}\right]
$$


Engle (2002) suggests the following mean-reverting conditionals with the GARCH(1,1) specification:

$$
\rho_{i j, t}=\frac{q_{i j, t}}{\sqrt{q_{i i, t} q_{j j, t}}}
$$

and CEE stock markets

where

$$
q_{i j, t}=\bar{\rho}_{i j}(1-\alpha-\beta)+\alpha e_{i, t-1} e_{j, t-1}+\beta q_{i j, t-1}
$$

And $\bar{\rho}_{i j}$ is the unconditional correlation between $e_{i, t}$ and $e_{j, t}$. Scalar parameters $\alpha$ and $\beta$ must satisfy,

$$
\alpha \geq 0, \beta \geq 0, \text { and } \alpha+\beta<1
$$

The value of $(\alpha+\beta)$ close to one reveals high persistence in the conditional variance.

In matrix form,

$$
Q_{t}=\bar{Q}(1-\alpha-\beta)+\alpha e_{t-1} e_{t-1}^{\prime}+\beta Q_{t-1}
$$

where $\bar{Q}=\operatorname{Cov}\left[e_{t}, e_{t}^{\prime}\right]=E\left[e_{t}, e_{t}^{\prime}\right]$ is unconditional covariance matrix of the standardized errors $Q$ can be estimated as,

$$
\bar{Q}=\frac{1}{T} \sum_{t=1}^{T} e_{t} e_{t}^{\prime}
$$

$R_{t}$ is then obtained by

$$
R_{t}=\left(Q_{t}^{*}\right)^{1 / 2} Q_{t}\left(Q_{t}^{*}\right)^{1 / 2}
$$

where $Q_{t}^{*}=\operatorname{diag}\left\{Q_{t}\right\}$.

Nevertheless, Aielli (2003) suggests that the estimation of the covariance matrix $Q_{t}$ is inconsistent because $E\left[R_{t}\right] \neq E\left[Q_{t}\right]$. He illustrates the following consistent model with the correlation-driving process (cDCC):

$$
Q_{t}=(1-\alpha-\beta) S^{*}+\alpha\left(Q_{t-1}^{* 1 / 2} \varepsilon_{t-1} \varepsilon_{t-1}^{\prime} Q_{t-1}^{* 1 / 2}\right)+\beta Q_{t-1},
$$

where $S^{*}$ is the unconditional covariance matrix of $Q_{t}^{* 1 / 2} \varepsilon_{t}$.

Engle and Kelly (2012) suggest modeling $\rho_{t}$ using the $\mathrm{CDCC}$ process to gain the conditional correlation matrix $Q_{t}$ and then taking the mean of its off-diagonal elements. DECO specification reduces the estimation time. The scalar equicorrelation can be written as:

$$
\rho_{t}^{\mathrm{DECO}}=\frac{1}{n(n-1)}\left(K_{n}^{\prime} R^{\mathrm{cDCC}} K_{n}-n\right)=\frac{2}{n(n-1)} \sum_{i=1}^{n-1} \sum_{j=i+1}^{n} \frac{q_{i j, t}}{\sqrt{q_{i i, t} q_{j j, t}}}
$$

Where $q_{i j, t}=\rho_{t}^{\mathrm{DECO}}+\alpha_{\mathrm{DECO}}\left(\varepsilon_{i, t-1} \varepsilon_{j, t-1}-\rho_{t}^{\mathrm{DECO}}\right)+\beta_{\mathrm{ECO}}\left(q_{i j, t}-\rho_{t}^{\mathrm{DECO}}\right), K$ is a vector of ones and $q_{i, j, t}$ is the $(i, j)$ th components of the matrix $Q_{t}$ from the DCC model. Then we apply $\rho_{t}^{\text {DECO }}$ to capture the conditional correlation matrix.

$$
R_{t}^{\mathrm{DECO}}=\left(1-\rho_{t}\right) I_{n}+\rho_{t} K_{n}
$$

where $I_{n}$ is the $n$-dimensional identity matrix.

Hence, the DECO modeling is less burdensome and computationally quicker to estimate. In addition, it reports the relationship of a group with a single DCC coefficient. 
EJMBE 30,2

\section{8}

Figure 1.

The framework of the methodology

\subsection{Quantile on Quantile approach}

The QQ approach was developed by Sim and Zhou (2015) as a generalization of the quantile regression, which identifies to investigate how the quantiles of an independent variable affect the provisional quantiles of the dependent variable. The $\mathrm{QQ}$ approach is employed on the combination of the nonparametric technique and quantile regression. More precisely, the connectedness between the two examined variables can be different at each point of the respective distributions.

In this paper, the QQ approach is utilized to model the impacts of the quantiles of Bitcoin prices on the quantiles of CEE stock markets. The following nonparametric quantile regression equation can be briefly written as

$$
S_{t}=\gamma^{\sigma}\left(\mathrm{BIT}_{t}\right)+\mu_{t}^{\sigma}
$$

where $\mathrm{BIT}_{t}$ represents Bitcoin returns at period $t, S_{t}$ denotes stock market returns of the CEE countries at period $t, \sigma$ is the $\sigma$ th quantile of the conditional distribution of Bitcoin prices, and $\mu_{t}^{\sigma}$ is the quantile error term whose conditional $\sigma$ th quantile is equivalent to zero. $\gamma^{\sigma}$ is an unidentified function as we have no prior information on the interplay between Bitcoin prices and CEE stock markets.

Such a quantile regression technique allows us to capture the changing impacts of Bitcoin price empirically across various quantiles of CEE stock returns. The primary advantage of this regression framework is to shed light on the efficient procedure of the dependency interplay between Bitcoin market and stock indices in the CEE countries.

The specific framework is presented in Figure 1.

\subsection{Data}

In this paper, we study the time-varying relationship between cryptocurrency and stock markets in the CEE region, our dataset includes time series of equity price indexes with daily frequency for a sample of S\&P 500 (SP), Bitcoin (BIT) and five stock markets in the CEE region: Hungary (BUX), Poland (WIG), the Czech Republic (PX), Romania (BET) and Croatia (CRON). Our study period spans from 6 September 2012 to 12 August 2019, yielding a total of 2,515 observations. Bitcoin data are obtained from https://www. coindesk.com/, and the rest of the financial assets are collected from Bloomberg terminal.

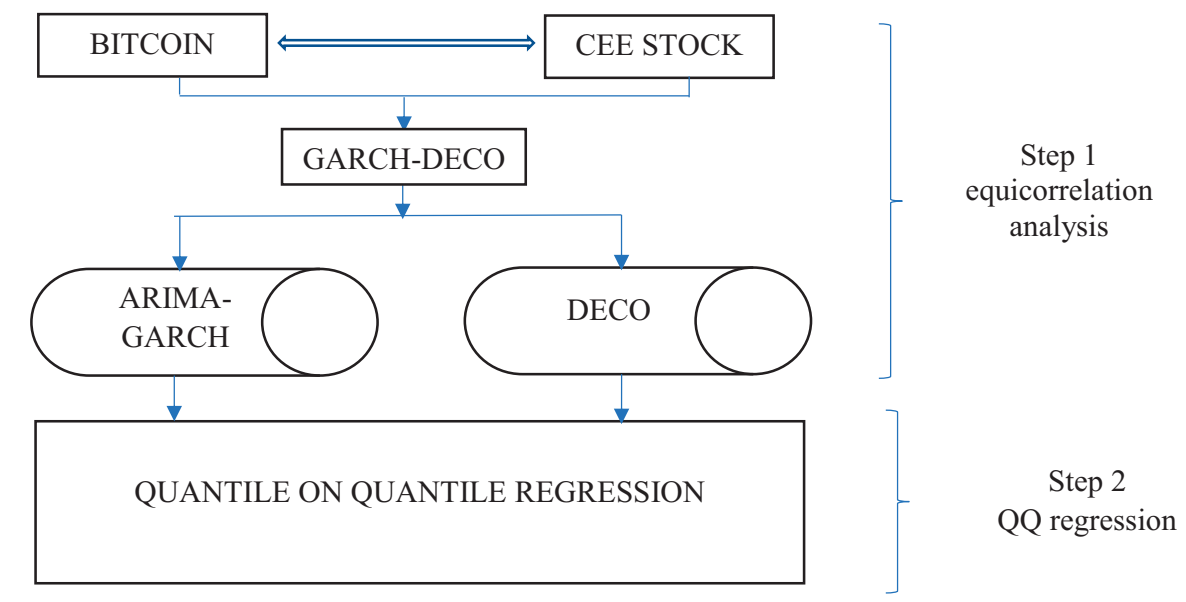


We calculate the log returns by taking the difference in the natural logarithm of two consecutive prices.

Our sample covers stock markets with various degree of financial development. Figure 2 shows the evolution of market size between 2015 and 2019 from the World Development Indicators. Market capitalization as a share of Gross Domestic Product reveals that stock markets in these countries have remarkably risen their relative significance over the period shown. Put it another way, it is worth noting the CEE's capitalization growth in recent years. In general, the largest stock market in the CEE was Poland, while the other members of the group had only deficient levels of market capitalization. Furthermore, the emerging stock markets of our sample have become more established and more mature through time. We observe that the developing markets in the selected economies with a relatively high and stable growth rate in the CEE region in recent years are significant, and they are frequently good choices for investors hunting for diversifying their portfolio globally (Hung, 2019, 2020).

More importantly, the CEE emerging markets examined in this study are those that joined the EU in 2004 (Poland, Hungary and the Czech Republic) and 2007 (Croatia and Romania). The reasons why we select these countries are that joined EU in 2004 along with the ones that joined the EU in 2007 to explore the difference between the CEE stock markets. Besides, we have chosen the CEE markets to observe if they have a connection with Bitcoin.

Table 2 represents the descriptive statistics for the log-returns of all seven variables under examination. It is obvious to observe that the means of all return series are near zero. The BIT and BET show the highest volatility, about 4.5 and $4.9 \%$, respectively. In addition, all return series are not normally distributed, with regard to the Jarque-Bera test for normality. Specifically, the augmented Dickey-Fuller (ADF) test demonstrates, for its part, that log returns are stationary. The ARCH test statistics reject the null hypothesis of no ARCH effects. All variables illustrate no evidence of serial correlation owing to the significance of the squared residuals $Q^{2}(10)$, which emphasizes the need to use the GARCH-DECO model in investigating them and is suitable for further statistical analysis.

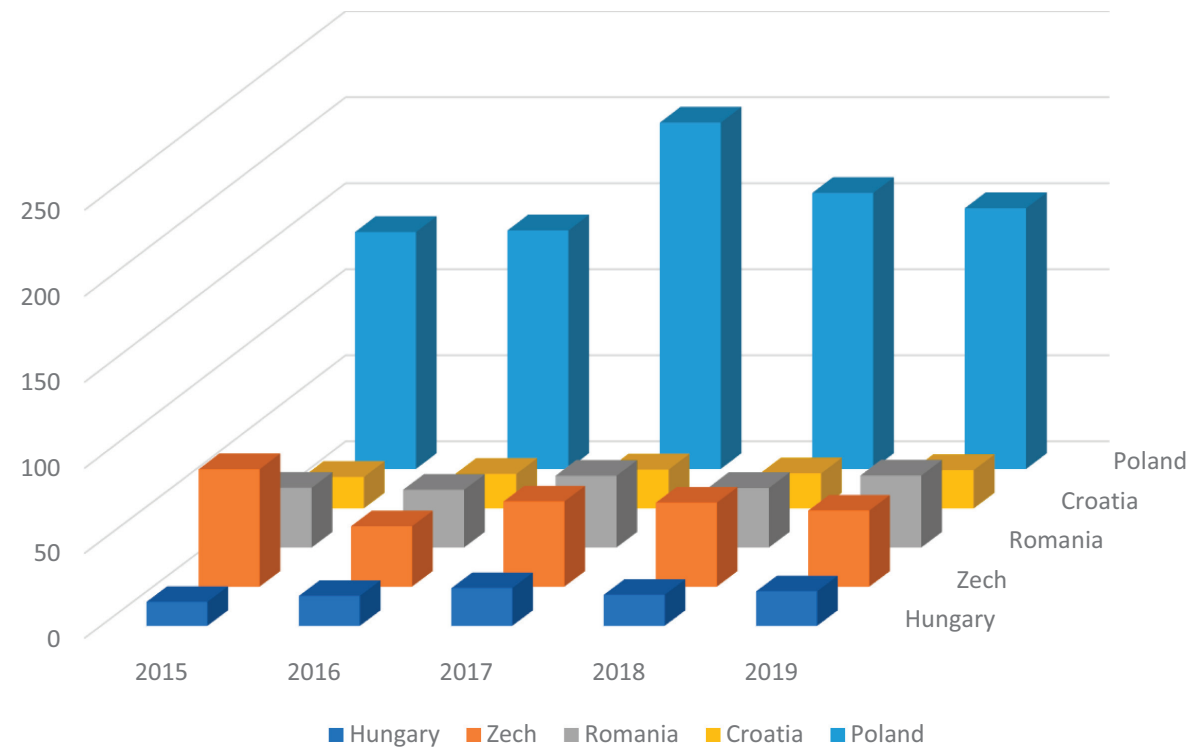

Bitcoin prices and CEE stock markets

269
Figure 2.

Market capitalization between 2015 and 2019

(\% of GDP) 
EJMBE
30,2

270

Table 2.

Descriptive statistics of daily returns over the in-sample period

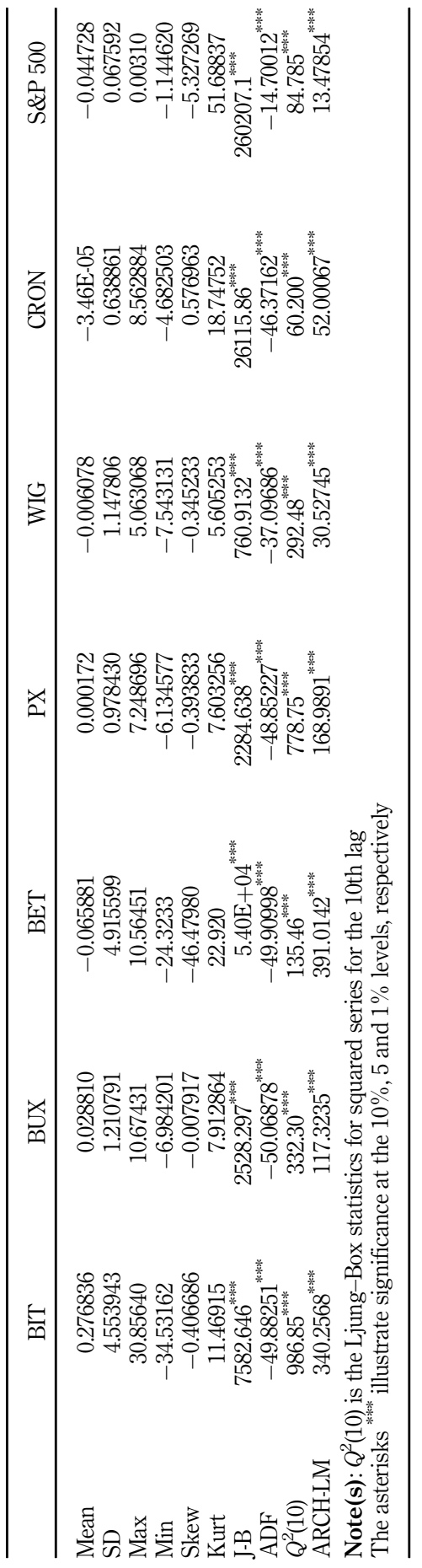


Figure 3 shows pairwise correlation coefficients across variables under consideration, while the price movements of all variables are introduced in Figure 4. A high correlation is not observed between the variables. All price series have demonstrated both increasing and decreasing trends over the sample period shown.

\section{Empirical results}

4.1 Estimation of the DECO-GARCH model

Table 3 reports the estimation results for the ARMA $(1,1)$-DECO-GARCH $(1,1)$ model among variables under study. The lag order of the $\operatorname{ARMA}(1,1)-\operatorname{GARCH}(p, q)$ has been selected to minimize the Akaike (AIC), Schwarz (SIC) information criteria to identify at an appropriate ARMA-GARCH model. We choose the univariate ARMA(1,1)-GARCH(1,1) for all combination returns.

In panel A of Table 3, the terms of ARCH and GARCH are statistically significant, and their sum is close to unity. This evidence shows a high persistence in the conditional volatility in BIT and the CEE stock markets. In panel B of Table 3 represents the results of the DECO model. The time-varying equicorrelation is positive and significant, with the value of 0.006726, which shows the presence of co-movement between the Bitcoin market and the CEE stock returns. The estimated DCC parameter $a_{\mathrm{DECO}}$ is positive and statistically significant for all the Bitcoin-stock markets, which implies the importance of shocks between Bitcoin market

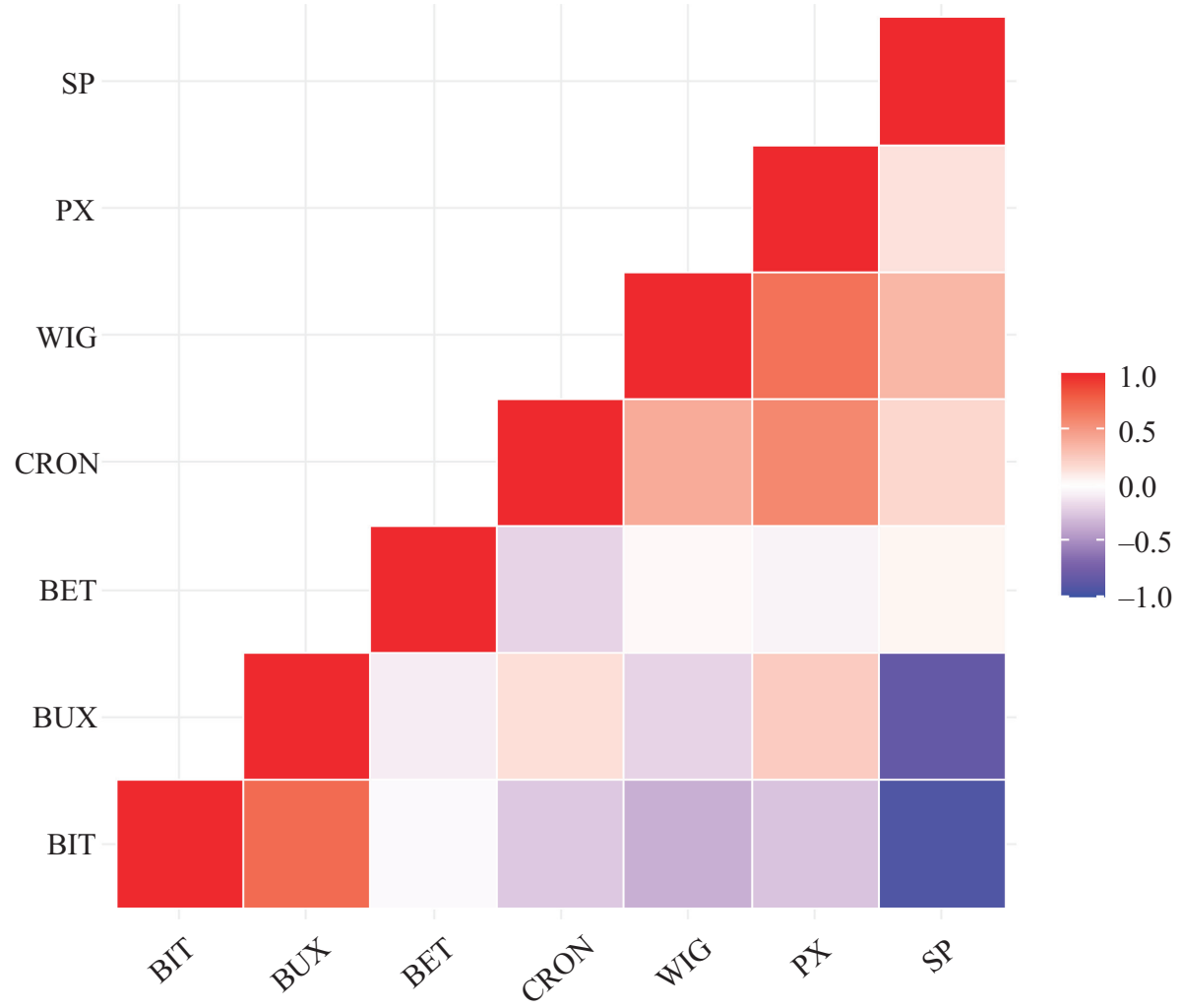

Figure 3. Heat map of pairwise correlations
Bitcoin prices and CEE stock markets 


\section{EJMBE 30,2}

\section{2}

Figure 4.

Plots of the data series
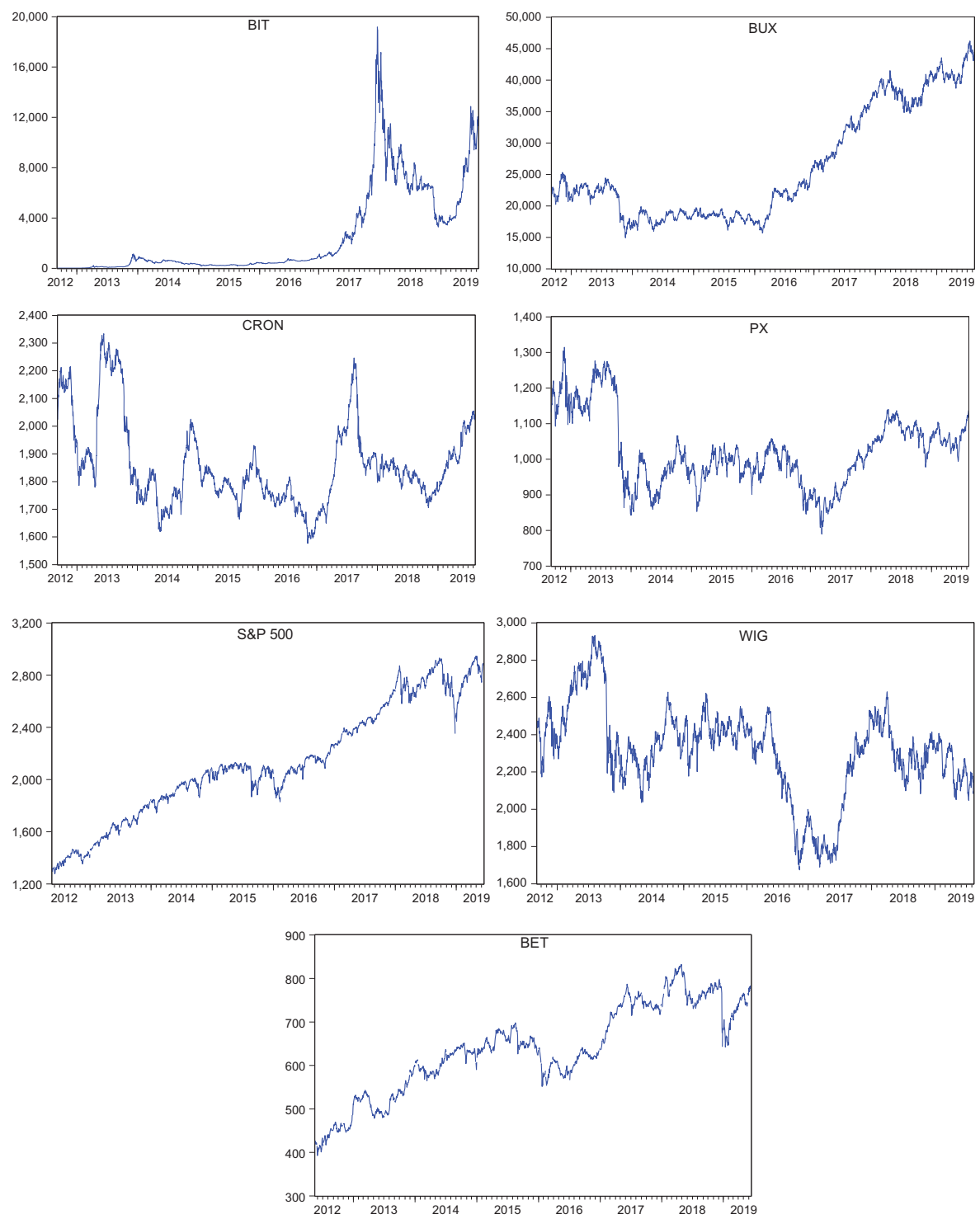

and CEE stock returns. More precisely, this result shows that market innovations have an impact on equicorrelations. In the same vein, the coefficient of $b_{\mathrm{DECO}}$ is statistically significant, confirming the existence of volatility across Bitcoin and CEE stock markets. Put it another way, equicorrelations are highly dependent on past correlations. Furthermore, the sum of $a_{\mathrm{DECO}}$ and $b_{\mathrm{DECO}}$ estimates is close to unity, suggesting that the volatility equicorrelation is integrated. Besides, the significance of the two parameters justifies the appropriateness of the DECO-GARCH model, and we could believe that the DECO parameters lie in the range of standard estimates stepping from $\operatorname{GARCH}(1,1)$ models. It 


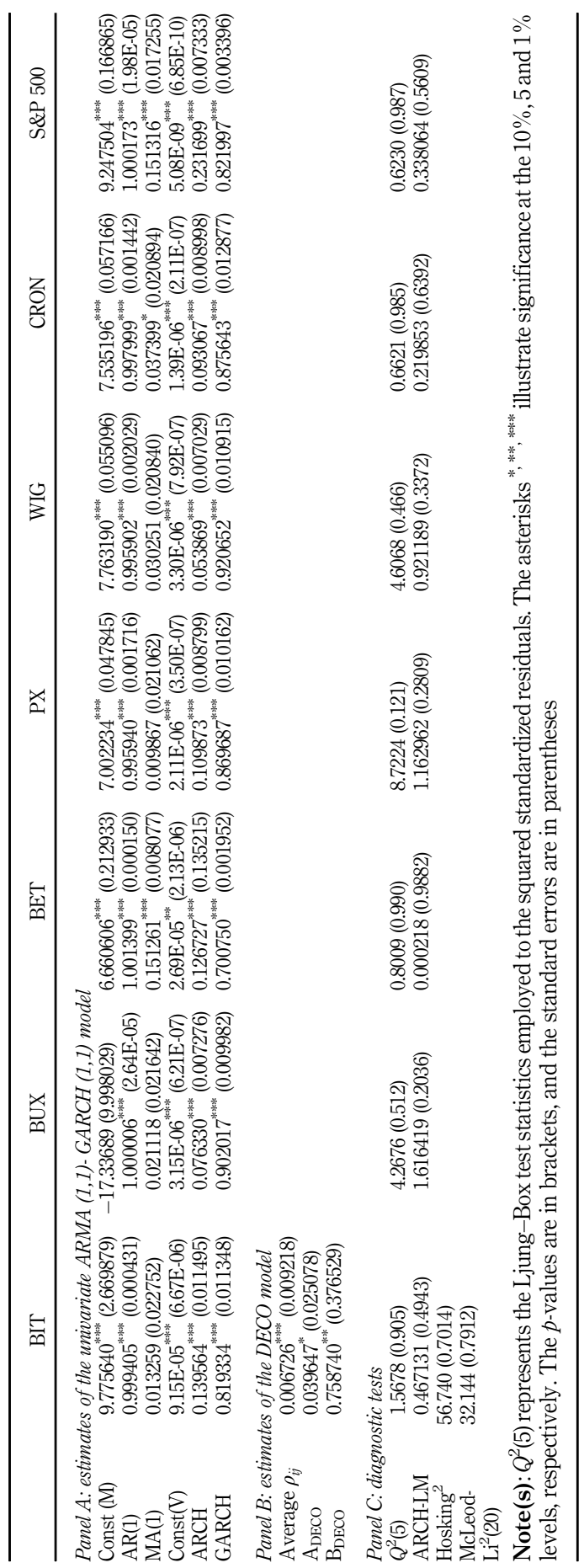

Bitcoin prices and CEE stock markets

273

Table 3. Estimation results of the ARMA-GARCH with DECO specification 
EJMBE 30,2

\section{4}

Figure 5.

Dynamic equicorrelation for returns Bitcoin and CEE stock markets simply means that the equicorrelation between Bitcoin return and CEE stock markets would be stable. These findings support the papers of (Kang et al. 2019a, b; Kang and Yoon, 2019).

Panel C performs the diagnostic tests that support the DECO-GARCH model's statistical appropriateness because of the insignificance of the Ljung-Box and ARCH-LM test statistics. We can conclude that there is no misspecification in our model. More importantly, the Hosking and McLeod and Li test results demonstrate that the null hypothesis of no serial correlation in the conditional variances estimated by the DECO-GARCH model is accepted, which supports the suitability of this model in the Bitcoin and CEE stock markets.

Figure 5 depicts the dynamic conditional equicorrelation across the CEE stock and Bitcoin markets, which is obtained from the ARMA-GARCH model with the DECO approach. Because the equicorrelation offers an idea of the correlation in the market, the DECO dynamics hold itself an interpretative value. As shown in Figure 5, the equicorrelation dramatically fluctuated over time, with a correlation level varying from a minimum of $-2.5 \%$ to a maximum of $12.5 \%$. Overall, Bitcoin-stock returns experienced a slight connectedness over the sample period shown.

To assess the robustness of the estimation results, we also estimate the dynamic correlational correlation (DCC) models between the returns of each CEE stock and the Bitcoin market as shown in Figure 6. Apparently, the pairwise DCC estimates support our findings gained for the CEE stock markets based on the DECO model.

\subsection{Quantile on Quantile estimates}

This section reports the main findings of the application of the QQ approach between Bitcoin market and CEE stock returns under analysis over the full sample. Figure 7 describes the slope estimates $\gamma_{1}(\theta, \tau)$ which quantify the influence of the $\tau$ th quantile of Bitcoin returns on oth quantile of stock markets in each CEE country, for an array of combinations of both variables. The slope coefficient estimates are presented on the $z$-axis, while the quantiles of CEE stock markets and Bitcoin prices lie on the $x$-and $y$-axes, respectively. A grid of 19 quantiles spanning from 0.05 to 0.95 with a step of 0.05 are considered for each indicator. Hence, the QQ framework offers a more complete and reliable description of the association structure between Bitcoin prices and CEE stock markets. It is clear from the figures that the interrelatedness between Bitcoin and CEE stock markets is not similar for all the countries. More precisely, there is significant heterogeneity across countries in connection with the BITCEE stock relationship.

In Hungary, the impact of Bitcoin prices on Budapest stock exchange is very small or even negative at low quantiles of Bitcoin returns. In fact, a comparative influence with the positive sign was found in the region that combines lower quantiles of stock markets $(0.05-0.5)$ with the link across all quantiles of Bitcoin prices $(0.05-0.30)$. In general, the effect of Bitcoin on the

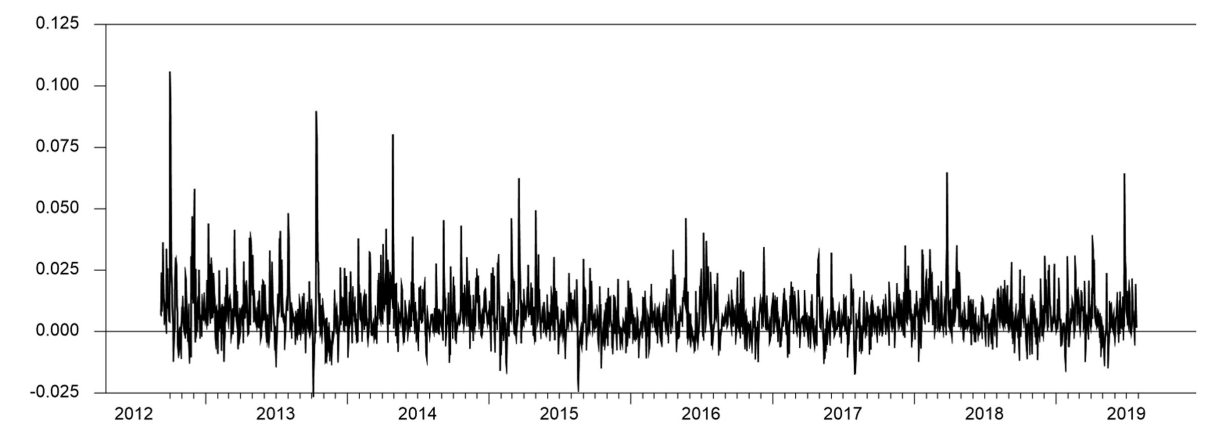



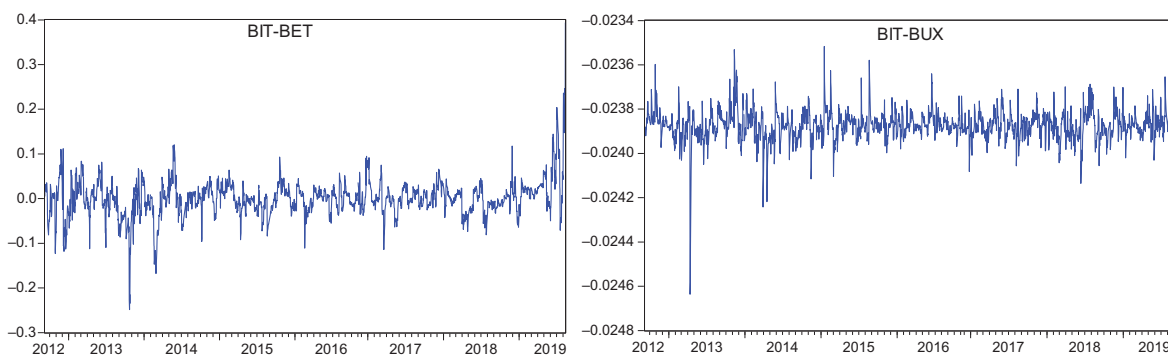

\section{Bitcoin prices and CEE stock markets}
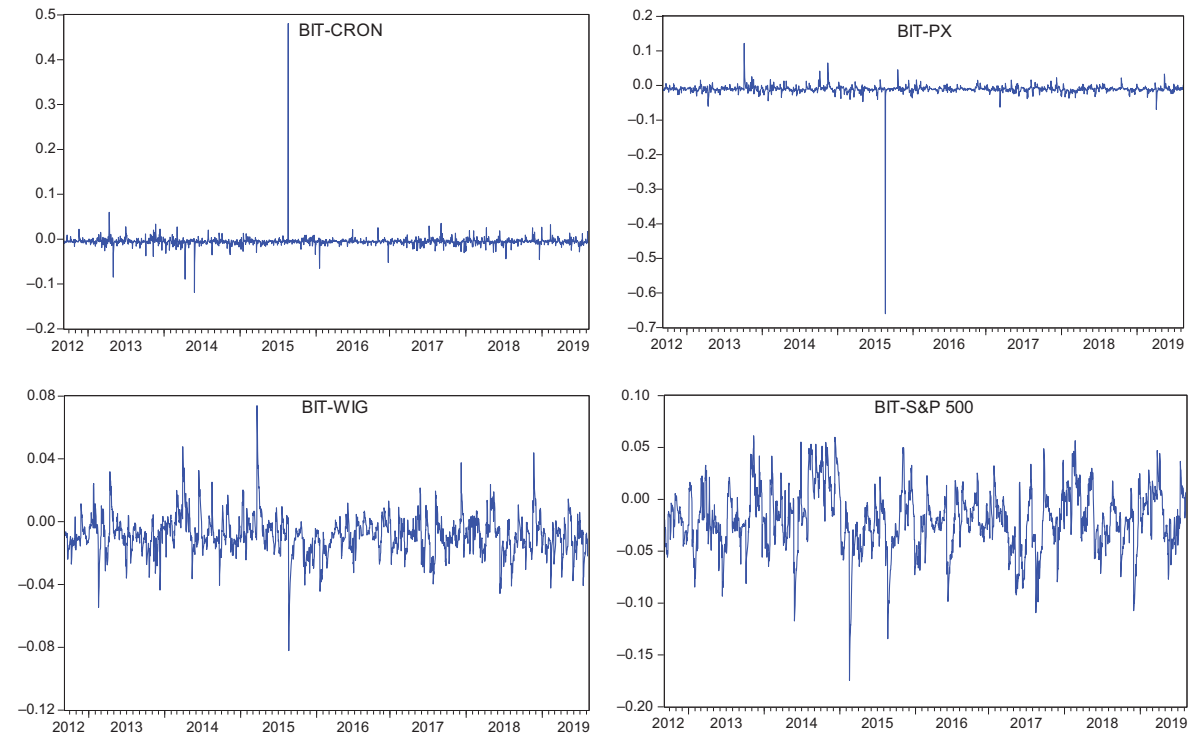

Figure 6.

Dynamic conditional correlation between Bitcoin and CEE stock markets

stock market in Hungary is weak across all the quantiles of stock markets. Nevertheless, the positive influence gets weaker on middle quantiles of Bitcoin prices. The somewhat low positive relationship observed in the remaining area can be explained in the sense that a slight increase in Bitcoin prices seems to raise stock returns in Hungary.

In Romania, the overall positive impact of Bitcoin prices on the stock market is found in the region that combines the lower to upper quantiles of Bitcoin prices $(0.05-0.95)$ with the lower to upper quantiles of the stock market (0.05-0.95). The Bitcoin prices and stock returns associations provide negative value for the different number of groups of quantiles, suggesting that there is a negative but weak impact of Bitcoin on the Bucharest Stock Exchange.

In the case of Croatia, the effect of Bitcoin prices on Zagreb stock exchange is positive for all quantiles of both variables. This positive impact is powerful at high quantiles of Bitcoin prices $(0.2-0.8)$ and moderate to high quantiles of stock returns $(0.4-0.8)$. However, the negative is also detected in both low and high the quantiles of Bitcoin prices. This result implies that the stock market in Romania is decreased during periods of low levels of Bitcoin volatility, while it is high during the periods of high levels of Bitcoin volatility. Therefore, the connectedness between the Bitcoin market and stock returns in Romania is not stable through time. 
EJMBE

30,2

\section{6}

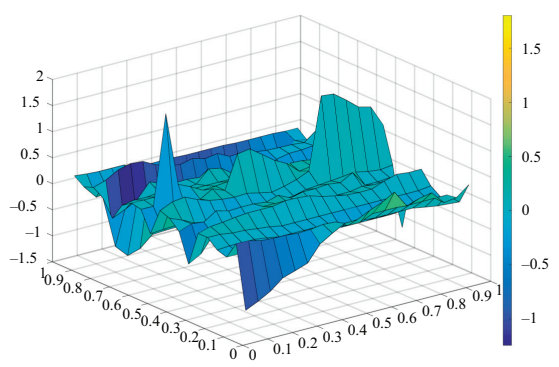

BIT-BUX

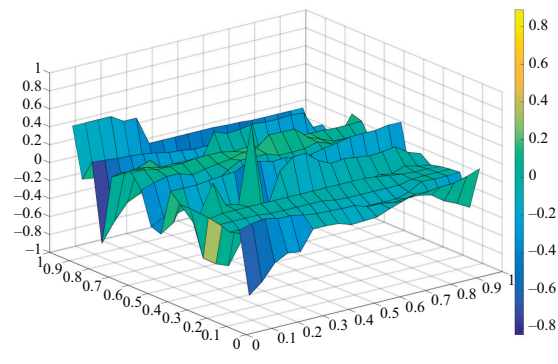

BIT-CRON

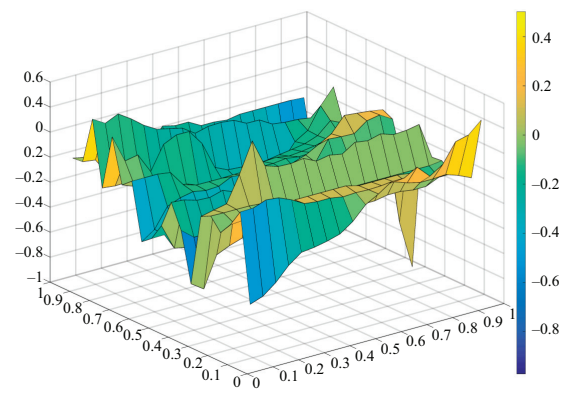

BIT-PX

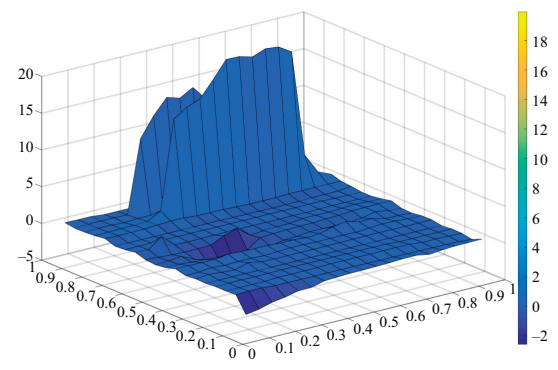

BIT-BEX

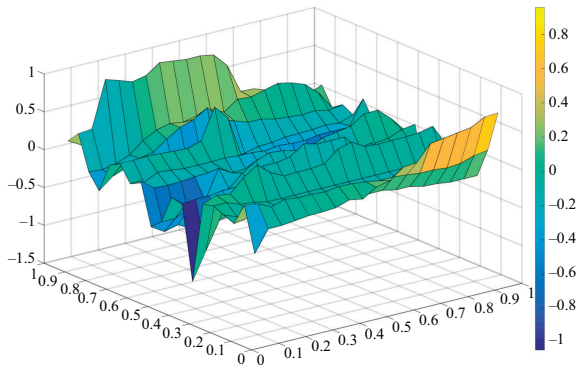

BIT-WIG

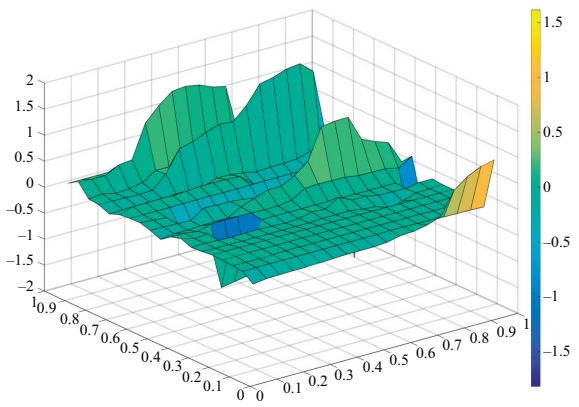

BIT-S\&P 500
Quantile-on-quantile (QQ) estimates 
This consequence highlights and quickly boosts the stock markets by Bitcoin prices which are described by the highest quantiles of Bitcoin prices.

Similarly, the effect of Bitcoin prices on the S\&P 500 is significantly positive. The impact is weak at low quantiles of Bitcoin prices and becomes relatively strong at the upper quantiles of Bitcoin variable, which means that there are unidirectional price spillovers from the Bitcoin market to the S\&P 500 index. The results validate the findings of López-Cabarcos et al. (2019) and Wang et al. (2020a).

Overall, Figure 7 summarizes the key findings of the $\mathrm{QQ}$ model, performing the combinations of quantiles of Bitcoin price changes and CEE stock returns which produce the most intense Bitcoin-stock market relationship for each country. It is clear that the strong positive relationship between Bitcoin and stock markets was found in the Czech Republic and Poland, while Hungary and Croatia experienced a weak correlation. However, the negative relationship was identified in Romania over the period shown. Our results support most of the literature that shows the significantly weak intercorrelation between Bitcoin prices and other conventional financial markets (Wang et al., 2020b; Zhang et al., 2021; Zeng et al., 2020). However, these findings contradict with the studies of Gil-Alana et al. (2020), Corbet et al. (2018), Zhang et al. (2018) and Bouri et al. (2019) who reveal the isolation of Bitcoin from the global financial system.

\section{Conclusion}

This paper aims to empirically address the dynamic linkages between changes in Bitcoin prices and stock returns for five CEE countries (Hungary, Poland, Czech Republic, Croatia and Romania) by employing both the multivariate DECO-GARCH model of Engle and Kelly (2012) and QQ methodology proposed by Sim and Zhou (2015). DECO refers to as a novel covariance matrix estimator, which bases on the assumption that any pair of variables is equicorrelated at every period, but this correlation varies over time. We use a $\mathrm{QQ}$ regression to examine the reaction of the CEE stock markets to different uncertainty proxies under various Bitcoin market conditions. In addition, the $\mathrm{QQ}$ approach goes a step further than the standard quantile regression, which captures the conditional dependence between Bitcoin and stock markets.

We find several impressive results. First, the findings show that the average return equicorrelation across Bitcoin prices and CEE stock indices are positive, even though it is found to be time-varying over the research period shown, with a correlation level varying from a minimum of $-2.5 \%$ to a maximum of $12.5 \%$. Second, the Bitcoin-CEE stock market association has positive signs for most pairs of quantiles of both variables and represents a rather similar pattern for the cases of Poland, the Czech Republic and Croatia. However, a weaker and primarily negative connectedness is found for Hungary and Romania, respectively. Furthermore, the interconnectedness between the co-movements in the Bitcoin market and stock returns changes significantly across quantiles of both variables within each nation, indicating that the Bitcoin-stock market relationship is dependent on both the cycle of the stock market and the nature of Bitcoin price shocks. This may reveal the presence of a nonlinear and asymmetric nexus between Bitcoin and CEE stock markets at the international level.

The evidence documented in this study has significant implications for divergent economic agents, including global investors, risk managers and policymakers, who would benefit from a comprehensive knowledge of the Bitcoin-stock market relationship to build efficient risk-hedging models and to conduct appropriate policy reactions to information spillover effects in different time horizons. More importantly, investors and portfolio managers should pay close attention to the conditions in stock and Bitcoin markets because the optimal capital allocation, diversification and risk hedging strategies might change dramatically depending on the specific phenomena in both markets. The findings also have
Bitcoin prices and CEE stock markets 
EJMBE 30,2

\section{8}

implications with regard to the design and implementation of procedures for monitoring and maintaining financial stability. Given the ability of Bitcoin price volatility to alter the risk of the stock markets, policymakers have to observe the Bitcoin market for the sake of financial stability in the CEE region by accurately assessing the Bitcoin-stock market relationship. By doing so, they may be able to take adequate measures at any given time with the purpose of restricting steady simultaneous decreases in Bitcoin and stock markets and hence, preserving financial and macroeconomic stability.

The significant level of bilateral links between Bitcoin and CEE stock markets found in this study might help the investor's choice of the asset class to invest in due to price spillovers. From a portfolio perspective, Bitcoin can contribute to the construction of better-diversified portfolios. Further, according to Paule-Vianez et al. (2020), Bitcoin would be a safe haven like gold, which allows investors to consider Bitcoin as a tool to protect their savings in times of economic uncertainty.

Despite the exciting idea, we neglected the causal associations between variables during the COVID-19 outbreak period, the effect of COVID-19 pandemics should be considered. Hence, in the future, we suggest expanding the research period covering the COVID-19 outbreak to unveil the connections between the examined asset classes in this paper and provide grounds for further research because the study on cryptocurrencies is at the experimental stage and requires more rigorous econometric techniques to construct stylized facts in the market.

\section{References}

Aielli, G.P. (2013), "Dynamic conditional correlation: on properties and estimation”, Journal of Business and Economic Statistics, Vol. 31 No. 3, pp. 282-299.

Antonakakis, N., Chatziantoniou, I. and Gabauer, D. (2019), "Cryptocurrency market contagion: market uncertainty, market complexity, and dynamic portfolios", Journal of International Financial Markets, Institutions and Money, Vol. 61, pp. 37-51.

Bouri, E., Lau, C.K.M., Lucey, B. and Roubaud, D. (2019), "Trading volume and the predictability of return and volatility in the cryptocurrency market", Finance Research Letters, Vol. 29, pp. 340-346.

Bouri, E., Vo, X.V. and Saeed, T. (2020), "Return equicorrelation in the cryptocurrency market: analysis and determinants", Finance Research Letters, Vol. 38, p. 101497.

Brauneis, A. and Mestel, R. (2018), "Price discovery of cryptocurrencies: bitcoin and beyond", Economics Letters, Vol. 165, pp. 58-61.

Corbet, S., Meegan, A., Larkin, C., Lucey, B. and Yarovaya, L. (2018), "Exploring the dynamic relationships between cryptocurrencies and other financial assets", Economics Letters, Vol. 165, pp. 28-34.

Corbet, S., Larkin, C., Lucey, B.M., Meegan, A. and Yarovaya, L. (2020), "The impact of macroeconomic news on Bitcoin returns", The European Journal of Finance, Vol. 26 No. 14, pp. 1396-1416.

Da Gama Silva, P.V.J., Klotzle, M.C., Pinto, A.C.F. and Gomes, L.L. (2019), "Herding behavior and contagion in the cryptocurrency market", Journal of Behavioral and Experimental Finance, Vol. 22, pp. 41-50.

Engle, R. (2002), "Dynamic conditional correlation: a simple class of multivariate generalized autoregressive conditional heteroskedasticity models", Journal of Business and Economic Statistics, Vol. 20 No. 3, pp. 339-350.

Engle, R. and Kelly, B. (2012), "Dynamic equicorrelation", Journal of Business and Economic Statistics, Vol. 30 No. 2, pp. 212-228.

Ferrer, R., Shahzad, S.J.H. and Maizonada, A. (2019), "Nonlinear and extreme dependence between long-term sovereign bond yields and the stock market: a quantile-on-quantile analysis", Economics Bulletin, Vol. 39 No. 2, pp. 969-981. 
Gil-Alana, L.A., Abakah, E.J.A. and Rojo, M.F.R. (2020), "Cryptocurrencies and stock market indices. Are they related?”, Research in International Business and Finance, Vol. 51, p. 101063.

Haseeb, M., Haouas, I., Nasih, M., Mihardjo, L.W. and Jermsittiparsert, K. (2020), "Asymmetric impact of textile and clothing manufacturing on carbon-dioxide emissions: evidence from top Asian economies”, Energy, Vol. 196, p. 117094.

Hung, N.T. (2019), "An analysis of CEE equity market integration and their volatility spillover effects”, European Journal of Management and Business Economics, Vol. 29 No. 1, pp. 23-40.

Hung, N.T. (2020), "Does volatility transmission between stock market returns of Central and Eastern European countries vary from normal to turbulent periods?", Acta Oeconomica, Vol. 70 No. 3, pp. 449-468.

Kang, S.H. and Yoon, S.M. (2019), "Financial crises and dynamic spillovers among Chinese stock and commodity futures markets", Physica A: Statistical Mechanics and its Applications, Vol. 531, p. 121776.

Kang, S.H., Uddin, G.S., Troster, V. and Yoon, S.M. (2019a), "Directional spillover effects between ASEAN and world stock markets", Journal of Multinational Financial Management, Vol. 52, p. 100592.

Kang, S.H., Yoon, S.M., Bekiros, S. and Uddin, G.S. (2019b), "Bitcoin as hedge or safe haven: evidence from stock, currency, bond and derivatives markets", Computational Economics, Vol. 56, pp. 1-17.

Kosc, K., Sakowski, P. and Ślepaczuk, R. (2019), "Momentum and contrarian effects on the cryptocurrency market", Physica A: Statistical Mechanics and its Applications, Vol. 523, pp. 691-701.

Koutmos, D. (2018), "Return and volatility spillovers among cryptocurrencies", Economics Letters, Vol. 173, pp. 122-127.

López-Cabarcos, M.Á., Pérez-Pico, A.M., Piñeiro-Chousa, J. and Šević, A. (2019), "Bitcoin volatility, stock market and investor sentiment. Are they connected?", Finance Research Letters, Vol. 38, p. 101399.

McIver, R.P. and Kang, S.H. (2020), "Financial crises and the dynamics of the spillovers between the US and BRICS stock markets", Research in International Business and Finance, Vol. 54, p. 101276.

Mensi, W., Rehman, M.U., Maitra, D., Al-Yahyaee, K.H. and Sensoy, A. (2020), "Does Bitcoin co-move and share risk with Sukuk and world and regional Islamic stock markets? Evidence using a time-frequency approach", Research in International Business and Finance, Vol. 53, p. 101230.

Omane-Adjepong, M., Alagidede, P. and Akosah, N.K. (2019), "Wavelet time-scale persistence analysis of cryptocurrency market returns and volatility", Physica A: Statistical Mechanics and its Applications, Vol. 514, pp. 105-120.

Paule-Vianez, J., Prado-Román, C. and Gómez-Martínez, R. (2020), "Economic policy uncertainty and Bitcoin. Is Bitcoin a safe-haven asset?", European Journal of Management and Business Economics, Vol. 29 No. 3, pp. 347-363.

Salisu, A.A., Isah, K. and Akanni, L.O. (2019), "Improving the predictability of stock returns with Bitcoin prices", The North American Journal of Economics and Finance, Vol. 48, pp. 857-867.

Shahbaz, M., Zakaria, M., Shahzad, S.J.H. and Mahalik, M.K. (2018), "The energy consumption and economic growth nexus in top ten energy-consuming countries: fresh evidence from using the quantile-on-quantile approach”, Energy Economics, Vol. 71, pp. 282-301.

Sim, N. and Zhou, H. (2015), "Oil prices, US stock return, and the dependence between their quantiles", Journal of Banking and Finance, Vol. 55, pp. 1-8.

Sinha, A., Shah, M.I., Sengupta, T. and Jiao, Z. (2020), "Analyzing technology-emissions association in Top-10 polluted MENA countries: how to ascertain sustainable development by quantile modeling approach", Journal of Environmental Management, Vol. 267, p. 110602. 
EJMBE 30,2
Tan, S.K., Chan, J.S.K. and Ng, K.H. (2020), "On the speculative nature of cryptocurrencies: a study on Garman and Klass volatility measure”, Finance Research Letters, Vol. 32, p. 101075.

Wang, J.N., Liu, H.C. and Hsu, Y.T. (2020a), "Time-of-day periodicities of trading volume and volatility in Bitcoin exchange: does the stock market matter?", Finance Research Letters, Vol. 34, 101243.

Wang, X., Chen, X. and Zhao, P. (2020b), "The relationship between Bitcoin and stock market", International Journal of Operations Research and Information Systems, Vol. 11 No. 2, pp. 22-35.

Wei, W.C. (2018), "Liquidity and market efficiency in cryptocurrencies", Economics Letters, Vol. 168, pp. 21-24.

Yi, S., Xu, Z. and Wang, G.J. (2018), "Volatility connectedness in the cryptocurrency market: is Bitcoin a dominant cryptocurrency?”, International Review of Financial Analysis, Vol. 60, pp. 98-114.

Zeng, T., Yang, M. and Shen, Y. (2020), "Fancy Bitcoin and conventional financial assets: measuring market integration based on connectedness networks", Economic Modelling.

Zhang, W., Wang, P., Li, X. and Shen, D. (2018), "The inefficiency of cryptocurrency and its crosscorrelation with Dow Jones Industrial Average", Physica A: Statistical Mechanics and its Applications, Vol. 510, pp. 658-670.

Zhang, Y.J., Bouri, E., Gupta, R. and Ma, S.J. (2021), "Risk spillover between Bitcoin and conventional financial markets: an expectile-based approach", The North American Journal of Economics and Finance, Vol. 55, 101296.

\section{Corresponding author}

Ngo Thai Hung can be contacted at: hung.nt@ufm.edu.vn

For instructions on how to order reprints of this article, please visit our website: 